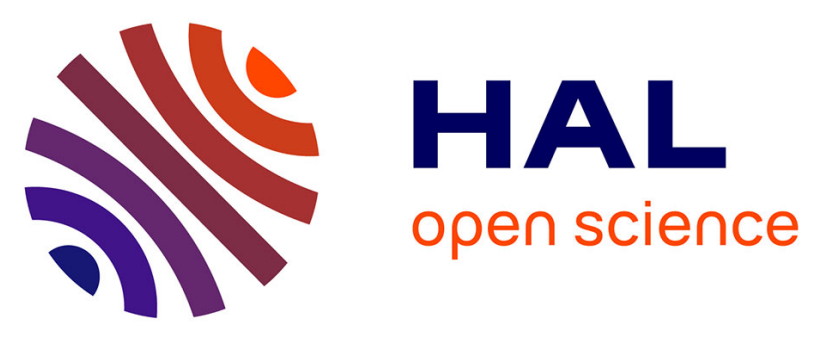

\title{
Non-host volatiles disturb the feeding behavior and reduce the fecundity of the green peach aphid, Myzus persicae
}

Tarek Dardouri, Laurent Gomez, Arnaud Ameline, Guy Costagliola, Alexandra Schoeny, Hélène Gautier

\section{To cite this version:}

Tarek Dardouri, Laurent Gomez, Arnaud Ameline, Guy Costagliola, Alexandra Schoeny, et al.. Nonhost volatiles disturb the feeding behavior and reduce the fecundity of the green peach aphid, Myzus persicae. Pest Management Science, 2021, 77, pp.1705-1713. 10.1002/ps.6190 . hal-03015172

\section{HAL Id: hal-03015172 \\ https://hal.inrae.fr/hal-03015172}

Submitted on 19 Nov 2020

HAL is a multi-disciplinary open access archive for the deposit and dissemination of scientific research documents, whether they are published or not. The documents may come from teaching and research institutions in France or abroad, or from public or private research centers.
L'archive ouverte pluridisciplinaire HAL, est destinée au dépôt et à la diffusion de documents scientifiques de niveau recherche, publiés ou non, émanant des établissements d'enseignement et de recherche français ou étrangers, des laboratoires publics ou privés.

\section{(ㅇ)(1) $\$$}

Distributed under a Creative Commons Attribution - NonCommercial - NoDerivatives| 4.0 


\section{Non-host volatiles disturb the feeding behavior and reduce the fecundity of the green peach aphid, Myzus persicae}

Running title: Companion plant volatiles disturb the reproduction of Myzus persicae

Tarek Dardouri ${ }^{1}$, Laurent Gomez ${ }^{1}$, Arnaud Ameline², Guy Costagliola ${ }^{1}$, Alexandra Schoeny ${ }^{3}$, Hélène Gautier ${ }^{1 *}$

${ }^{1}$ UR1115 PSH Plantes et Systèmes de Culture Horticoles, INRAE, F84914, Avignon, France ;

${ }^{2}$ UMR CNRS 7058 EDYSAN (Écologie et Dynamique des Systèmes Anthropisés), Université de Picardie Jules Verne, 33 Rue St Leu, 80039 Amiens Cedex, France ;

${ }^{3}$ Pathologie Végétale, INRAE, 84140, Montfavet, France.

*Author to whom correspondence should be addressed:

Hélène Gautier, INRAE Centre de Recherche PACA UR 1115. Plantes et Systèmes de culture Horticoles (PSH). 228 route de l'Aérodrome CS 40509, Domaine Saint Paul - Site Agroparc, 84914 AVIGNON Cedex 9, France. Tel.: +33 (0)4 327223 45. E-mail address: helene.gautier@inrae.fr

This article has been accepted for publication and undergone full peer review but has not been through the copyediting, typesetting, pagination and proofreading process which may lead to differences between this version and the Version of Record. Please cite this article as doi: $10.1002 /$ ps.6190

This article is protected by copyright. All rights reserved. 


\begin{abstract}
BACKGROUND:

The association of crops of value with companion plants could be one of the strategies to reduce the harmful effects of pests. We hypothesize that volatile organic compounds (VOCs) emitted by some aromatic plants may negatively impact $M$. persicae, disturbing its feeding behavior and consequently its reproduction.
\end{abstract}

\title{
RESULTS:
}

VOCs emitted from six potential companion plant species affected the reproduction of $M$. persicae feeding on pepper plants, Capsicum annuum. Reproduction of $M$. persicae was reduced when exposed to VOCs from leaves of Ocimum basilicum and flowers of Tagetes patula. Thus, species and phenology of the companion plant can influence the effect. The VOCs from O. basilicum and T. patula also reduced phloem feeding by the aphids based on electropenetrography (EPG).

\section{CONCLUSION:}

The reduced fecundity of $M$. persicae could be linked to aphid feeding disruption provoked by the VOCs emitted by $O$. basilicum in the vegetative stage or $T$. patula $\mathrm{cv}$. Nana in the flowering stage.

Keywords: Companion plants (CPs); electropenetrography (EPG); Ocimum basilicum; pest; reproduction; volatile organic compounds (VOC)

\section{INTRODUCTION}

In order to reduce the use of chemical inputs, the implementation of more environmentally friendly integrated pest management (IPM) programs has become essential. ${ }^{1,2}$ Of the ecological approaches, the introduction of companion plants (CPs), which are repellent and/or disruptive to pest establishment, planted in association with or 
near the crop to be protected, can reduce pest abundance and damage in agrosystems. , $^{3,4}$ Volatile organic compounds (VOCs) emitted from companion plants are mainly responsible for these effects. ${ }^{5}$

VOCs are olfactory signals that play an important role in the chemical ecology of aphids, particularly in locating the host plant and estimating the quality of its habitat. ${ }^{6}$ In nature, the aphid perceives attractive or neutral VOCs, ${ }^{6,7}$ but also repellent or disruptive ones, ${ }^{8,9}$ generally emitted by non-host plants. In addition to repelling the winged aphid during the phase of locating its host plant, these volatiles can also cause the apterous aphid to flee, even after it has settled on its host plant. In the absence of a significant repellent effect, certain odor bouquets may also result in reduced fecundity of aphids. ${ }^{9}$ Indeed, the performance of an aphid varies according to the particularities of the host plant, but also according to its environment. Under favorable conditions for optimal population growth dynamics, several studies have shown that exposure of the aphid to certain VOCs, or the blend of VOCs from different sources (whole plants, essential oils, plant extracts or individual compounds), adversely affects its reproduction. ${ }^{9-13}$

The selection of a $\mathrm{CP}$ for pest management requires understanding the mechanisms through which the CP disrupts pest behavior. Although it is generally assumed that CP VOCs repel target pests or interfere with their host finding behavior, VOCs also potentially interfere with settling and sustained feeding and reproduction on the local crop. Post-alightment effects of CP on pests have scarcely been investigated. ${ }^{14}$

The aim of this work is to study, under laboratory conditions, the effect of volatiles of different candidate CPs on Myzus persicae associated with pepper (Capsicum annuum L.). Based on a previous study ${ }^{9}$, six CPs with proven repellent activity were tested to determine the impact of their VOCs on aphid fecundity: marigold (Tagetes patula L.) (Asteraceae), basil (Ocimum basilicum L.), lavender (Lavandula latifolia L.), rosemary 
(Rosmarinus officinalis L.) and peppermint (Mentha piperita L.). In a second step, VOCs from CPs affecting aphid fecundity were (1) tested for their effect on aphid feeding behavior by using electropenetography (EPG) and (2) analyzed via GC-MS to determine the chemical composition of emitted blend.

\section{MATERIAL AND METHODS}

\subsection{Insects}

Myzus persicae (clone Mp05) was reared on young pepper plants under controlled conditions (22 $\pm 1{ }^{\circ} \mathrm{C}, \mathrm{RH}=60 \%-70 \%, 16 \mathrm{~L}: 8 \mathrm{D}$ photoperiod). In order to obtain individuals of the same age, aphid rearing was synchronized. For fecundity tests, we used 5-day-old nymphs (stage L3-L4). EPG experiments were performed with 10-day-old apterous females.

\subsection{Plant species}

We tested five aromatic species as CPs: basil (Ocimum basilicum L., cv. Marseillais), lavender (Lavandula latifolia L., cv. Séguret), peppermint (Mentha piperita L., cv. Officinalis), rosemary (Rosmarinus officinalis L., cv. Voltz Splindler) (Lamiaceae) and two varieties of marigolds (Tagetes patula L., cv. Nana and Bonita Bolero) (Asteraceae). ${ }^{8}$ As the host plant of $M$. persicae we used 6-week-old pepper plants (Capsicum annuum L., cv. Yolo Wonder) (5-6 developed leaves). The CPs and pepper plants were grown in two different glasshouses $\left(20 \pm 5{ }^{\circ} \mathrm{C}\right.$ and $\left.\mathrm{RH}=60-70 \%\right)$ to avoid VOC-related interactions between CPs and host plants. With the exception of L. latifolia (3 L pots), all plants were grown in plastic pots $(90 \times 90 \times 100 \mathrm{~mm})$ containing commercial sterilized potting soil (Klasmann-Deilmann ${ }^{\circledR}$ ). No fertilizers or chemical treatments were applied. 


\subsection{Effect of volatile organic compounds on the fecundity of Myzus persicae}

The fecundity rate of M. persicae in the presence of VOCs emitted by the CPs was compared under laboratory conditions (22 $\pm 1{ }^{\circ} \mathrm{C}$ and photoperiod 16L:8D) to that observed in the presence of exclusively pepper leaves (control).

At the bottom of a Petri dish (155 $\mathrm{mm}$ in diameter $\times 25 \mathrm{~mm}$ high), a pepper leaf was attached (abaxial side up) to an agar medium (2\% agar-agar). ${ }^{11,15}$ For the control, a single pepper leaf was placed in a dish. For the CP treatments, $3 \mathrm{~g}$ of leaves or $3 \mathrm{~g}$ of flowers $(\approx$ the weight of one flower of $T$. patula) of the CPs were placed in the other half of the Petri dish (Figure S1). One hour after depositing the CPs and control plants in the Petri dish, a 5-day-old nymph was deposited on the pepper leaf using a brush. The Petri dish was then closed and turned over so that the aphid was positioned on the underside of the leaf.

After 3 days, aphids reach the adult stage and their larvipositions begin. After this, for 5 days (D4-D8), the nymphs produced were counted and eliminated daily (between 10:00 am and 11:00 am). Each treatment was repeated 30 times and compared to the control performed at the same time. With the exception of $R$. officinalis and M. piperita (only the leaves were available), the leaf and flowers of six CPs were tested.

\subsection{Qualitative analysis of volatile compounds by gas chromatography coupled with mass spectrometry (GC-MS)}

To establish a link between CPs and aphid fecundity, VOC mixtures released from different aerial parts (leaves or flowers) were trapped by solid-phase microextraction (SPME) and analyzed by GC-MS (Figure S1. The measurements were taken 
simultaneously under the same experimental conditions described for the fecundity tests but in Petri dishes without aphids.

A small opening $(<1 \mathrm{~mm}$ ) made on the wall of the Petri dish allowed introduction of a SPME fiber (PDMS-DVB, $65 \mu \mathrm{m}$; Supelco, Bellefonte, USA) and to take a representative sample of the olfactory mixture for $30 \mathrm{~min}$. The SPME fiber was then removed and the sample was subsequently analyzed. Five replicates were performed per treatment, i.e. one extraction and analysis per day (from D4 to D8), at 11:00 am.

For comparison, olfactory mixtures produced by whole plants were also sampled using a dynamic device in controlled conditions (according to the protocol described by Dardouri et al.). ${ }^{8}$ For each sample, six plants were carefully introduced, without touching the foliage, inside a glass cage. An airflow $\left(8 \mathrm{~L} \mathrm{~min}^{-1}\right.$, filtered through an active charcoal filter) was pumped by a compressor to each glass cage containing the odor sources. After two hours of stabilization, a SPME fiber (PDMS-DVB, $65 \mu \mathrm{m}$ ) was introduced into the air stream for 30 min of exposure. Sampling was carried out at 11:00 am. Between each repetition, the cage was cleaned first with ethanol (70\%) and then with distilled water, and subsequently dried and thoroughly ventilated.

The extracted VOC mixtures were analyzed by GC-MS (Trace-ISQ, single quadrupole (Thermo Scientific, Austin, TX, USA)) equipped with a TR-5MS non-polar column (20 m, $0.1 \mathrm{~mm}$ ID, $0.1 \mu \mathrm{m}$ film thickness) according to the method described by Dardouri et al. ${ }^{8}$ Volatiles were identified using the Thermo Xcalibur software by comparing their mass spectra with those from the NIST 2011 library (National Institute of Standards and Technology, Gaithersburg, MD, USA). The retention times of the majority of the compounds to be identified were verified by pure commercial standards (Sigma Aldrich ${ }^{\circledR}$ ). 


\subsection{Study of the feeding behavior of Myzus persicae by electropenetrography (EPG)}

To understand whether the presence of VOCs released from CPs changes the feeding behavior of aphids on peppers, we applied the EPG technique. ${ }^{16,17}$ This technique allows in situ assessment of the feeding behavior of "piercing-sucking” insects, usually phloemophagous hemipterans such as aphids. The EPG technique consists of integrating an aphid and a plant into an electrical circuit (Figure 1.A). First, a copper electrode implanted in the substrate of each plant tested was connected to a current generator. A second electrode, connected to an aphid by a gold wire (diameter $=20 \mu \mathrm{m}$, length $=2 \mathrm{~cm}$ ) fixed on the insect's back (on the abdominal tergites) with conductive silver glue, was connected to an amplifier connected to a computer (EPG Systems, Wageningen, The Netherlands). The penetration of the stylets into plant tissue allows the current to flow which is amplified and displayed as waves on an electrical penetration graph (Figure 1.B). These recorded waves vary depending on the position of the stylets within the plant tissue and on different feeding activities. Different characteristic waveforms were analyzed in this study, namely: i) C waves: phase of search for phloem cells and transition of the stylet through epidermal, parenchymal and mesophyllic tissues; ii) E1 waves: salivation in a sieve tube; iii) E2 waves: passive ingestion of elaborated sap (phloem), of which those sustained for more than 10 minutes have been called sE2 waves; iv) G waves: active ingestion of xylem sap; v) F waves: derailment of the stylet in the plant tissues caused by mechanical stress, "potential drop”, and intracellular punctures in the parenchymal cells. A potential drop is subdivided into 3 sub-phases (II.1, II.2 and II.3). ${ }^{17}$ The first sub-phase (II.1) represents the injection of aqueous saliva into the punctured cell, the second subphase (II.2) is still unknown and the third sub-phase (II.3) represents intracellular ingestion. ${ }^{18}$ The EPG device used for this study consists of eight channels (EPG-Giga-8d, 
Wageningen University, The Netherlands) which registers simultaneously the feeding activities of eight aphids on eight plants.

On the morning of the experiment, pepper plants and CPs were placed according to the treatment to be tested in an air-conditioned room $\left(22^{\circ} \mathrm{C} \pm 1^{\circ} \mathrm{C}\right.$, equipped with an extractor) inside a Faraday cage. The Faraday cage attenuates electromagnetic interference. A copper electrode connected to a direct current generator was implanted in the substrate of each plant.

The EPG test started 4 hours after the plants had been introduced into the device. Eight aphids were used after fasting for one hour in Petri dishes on wet filter paper. As soon as the signal acquisition at $100 \mathrm{~Hz}$ frequency was triggered using the software Stylus+ daq v01.27 (EPG Systems, www.epgsystems.eu), the aphids were gently placed on a pepper leaf. Continuous recordings of feeding activity were taken for 8 hours.

Once the recordings were made, the electropenetrograms were analyzed using the EPG Stylet+ ana (v01.27) software (EPG Systems, www.epgsystems.eu), and the various characteristic waveforms were determined. Using the recorded waveform analyses, various EPG parameters were calculated using the EPG-Calc 6.1.6 software. ${ }^{19}$ Only eighteen parameters were selected for this study (Table 3).

Using the EPG device, we followed the feeding behavior of $M$. persicae in the presence of the two plant treatments which had caused a significant decrease in fecundity of $M$. persicae, $O$. basilicum at the vegetative stage and $T$. patula $\mathrm{cv}$. Nana at the flowering stage. A CP was placed $30 \mathrm{~cm}$ from the pepper leaf on which the aphid was deposited. The control condition consisted of replacing the CPs with pepper plants. For each of the three tested treatments, 35 individual replicates were carried out. Only one repetition of a treatment was tested per day. The dates of experimentation for each treatment were randomized to limit the impact of any source of variability (batch of 
plants, aphids, among others). To avoid contamination, the room was ventilated and unused for a minimum of 3 days for each change in the modality to be tested.

\subsection{Statistical analysis}

The statistical analyses were performed using R software (version 3.1.0). Since the conditions of normality and homogeneity of variance were not met, the nonparametric Mann-Whitney U-test $(\alpha=0.05)$ was used to compare the daily fecundity rate for each treatment with that of the respective control (pepper leaf alone). The same statistical test was used to compare the EPG data from two modalities (CPs vs. control).

\section{RESULTS}

\subsection{Effect of volatile organic compounds on the daily fecundity of Myzus persicae}

The control curves presented in Figure 2 show the daily fecundity of females on pepper leaf in the absence of CPs. At D4, the first day of oviposition, this rate ranges from 1 to 3 nymphs laid per day depending on the experiments. It increases rapidly the following day and reaches a value that stabilizes between D5 and D6, and is maintained at D7 and D8 at a value between 6 and 8 nymphs laid per day, per female. The same profile is found for all controls tested, which validates the protocol used to test the effect of CPs on fecundity.

Regardless of the CP tested, there is no significant difference in the fecundity rate at D4 between the control and the CP tested. After D5, the reproductive rate of $M$. persicae on plants near $O$. basilicum leaves and near T. patula flowers declined relative to controls (Figure 2.E). The effect was significant for O. basilicum on D6, D7, and D8 $(P=0.001$ to D6; $P=0.03$ to D7; $P=0.009$ to D8) and for T. patula cv. Nana on D5 and D8 $(P=0.01, P=0.0003, P<0.0001, P=0.0003$, between D5 and D8, respectively, 
Figure 2.B). Aphid reproduction also declined significantly on plants near L. latifolia flowers on D7 ( $P=0.01$, Figure 2.H). Aphid fecundity was not affected by other treatments (Figure 2.A, 2.C, 2.D, 2.F, 2.G, 2.I, and 2.J). During the five days of monitoring, a $19.3 \%$ decrease in the number of nymphs laid in the presence of $O$. basilicum leaves, and $23.6 \%$ in the presence of flowers of $T$. patula $\mathrm{cv}$. Nana were recorded. No significant effects were observed $(P>0.05)$ in the presence of flowers or leaves of a second variety of T. patula (Bonita Bolero, Figures 2.C and 2.D).

\subsection{Characterization of the profile of volatile organic compounds}

Under the two conditions where a decrease in fecundity was observed (leaf of $O$. basilicum and flower of T. patula cv. Nana), qualitative analyses of VOC profiles emitted were performed in Petri dishes and compared to the profiles emitted by whole plants. Thus, in Petri dishes containing a flower of T. patula cv. Nana, only 11 of the 30 compounds identified on whole plants were found (Table 1). The profile of VOCs released from the leaf of $O$. basilicum deposited in the Petri dish (23 VOCs) was nearly similar to that of the whole plant in the vegetative stage, with only aromandendrene and (Z)- $\beta$-farnesene being absent (Table 2).

\subsection{Effect of volatile organic compounds from companion plants on the feeding behavior of Myzus persicae}

Table 3 shows the significant effect of VOCs emitted from whole plants of $O$. basilicum (vegetative stage) and T. patula cv. Nana (flowering stage) on 13 of the 18 parameters characterizing the feeding behavior of $M$. persicae on pepper. During the 8 hours of recording (480 min), the number of stylet insertions (Pr, parameter 1 ) is doubled in the presence of CPs (20.7 and 22.1 respectively with O. basilicum and T. patula) 
compared to the control (11.8), and the total duration of stylet penetration (parameter 2) is significantly shorter $(P<0.03)($ control $=448.2 \mathrm{~min}$; $O$. basilicum $=428.5 \mathrm{~min} ; T$. patula $=421.3 \mathrm{~min})$. In the presence of CPs, aphids spend more time in the search phase, due to an increase in the number $(\mathrm{C}$, parameter 4 , by $+70.7 \%$ with $O$. basilicum and $+77.6 \%$ with $T$. patula) and duration (parameter 5 , by $+48.3 \%$ with $O$. basilicum and $+58.4 \%$ with $T$. patula) of this phase. The total duration of elaborated sap ingestion (parameter 10) was significantly shorter $(P<0.0005)$ in the presence of CPs (about $45 \%$ with O. basilicum and 35\% with T. patula).

The effects of CPs differed. Tagetes patula had no effect on the salivation phases (E1), whereas the proximity of O. basilicum increased the number of E1 not followed by an ingestion phase (parameter 6: $+75 \%$ ) and the total duration of E1 (parameter 7, $+139 \%)$. Only $T$. patula significantly $(P<0.03)$ increases the number of stylet insertions $(+38 \%)$ before the first sustained ingestion of elaborated sap (sustained E2, parameter 9). The time elapsing before the 1st phase of ingestion of sustained elaborated sap ( $>10 \mathrm{~min}$, parameter 11) increases significantly $(P<0.002)$ only in the presence of $O$. basilicum volatiles (+100\%). Other measured parameters are not affected by the proximity of the CPs (Table 3).

Concerning the parameters related to potential drops (pd) (intracellular stylet punctures), the number of pd (parameter 14) increased in the presence of CPs but this increase was not significant, whereas the total duration of pd was significantly longer in the presence of $T$. patula VOCs (+38\%), but not in the presence of O. basilicum (+36\%). For the different pd sub-phases (II.1, II.2 and II.3), durations were significantly longer in the presence of $T$. patula $(+37.5 \%,+38.1 \%$, and $+44.4 \%$, respectively). However, only the duration of sub-phase II.3 increased significantly in the presence of O. basilicum VOCs $(+44.4 \%)$. 


\section{DISCUSSION}

The main purpose of this study is to provide knowledge on the mechanisms of action of CPs on aphid behavior, and more specifically to test the hypothesis that the VOCs emitted by these plants could modify the aphid's feeding behavior and fecundity.

This study allowed also to propose an adaptation and a validation of a simple and quick test in a Petri dish ${ }^{11,15}$ that proves to be repeatable and effective in alighting the effect of VOCs emitted by a plant organ (leaf or flower) on aphid fecundity. Our results confirm the earlier work by Ben Issa et al ${ }^{9,13}$ carried out on whole plants that VOCs from O. basilicum and T. patula significantly reduce the fecundity of M. persicae. By contrast, no effect was detected with VOCs released by L. latifolia, $R$. officinalis and M. piperita on $M$. persicae fecundity. Therefore, the use in our experiment of (1) detached plant organs and (2) different chemotypes of these three species than used by Ben Issa et al., ${ }^{9,13}$, could explain this discrepancy.

The contrasting effect on $M$. persicae fecundity of the two chemotypes of marigold tested corroborates other reports of different effects among plant chemotypes on pests. ${ }^{20-23}$ We have also verified that the aerial organs of a plant, in this case the leaf and the flower, may emit different olfactory mixtures and therefore not have the same effect on the performance of M. persicae.. Therefore, the phenology of CPs, which can affect their VOC emissions ${ }^{24,25}$ should be a consideration when deploying them for pest management. Our results suggest that $O$. basilicum at the vegetative stage and $T$. patula at the flowering stage would be most effective as CP to reduce $M$. persicae infestations, by disrupting feeding and reproduction by the aphid.

The decrease in $M$. persicae fecundity in the presence of CP VOCs could result from disruption of aphid feeding as detected with our EPG results. We hypothesize that 
detection of CP VOCs by the aphids' accounts for the observed reduction in their sustained feeding and increases in nonproductive probing and searching, leading to overall reduced rates of phloem ingestion.

Few works alighted the interruption of feeding behavior of $M$. Persicae in response to VOCs. In the present study, we demonstrate that the food intake of $M$. persicae is frequently interrupted, and that it is disturbed before reaching the phloem and the frequency and duration of the salivation phases are significantly more important in the presence of CPs. A similar behavior of M. persicae reared on Chinese cabbage was reported by Dancewicz et al., ${ }^{26}$ in the presence of camphene and $\beta$-ionone. In addition, Hu et al. ${ }^{27}$ had already made a similar hypothesis of a possible link between a disturbance in the feeding behavior of Aphis gossypii and the production of new volatile or nonvolatile compounds by the host plant. Bermingham et al. ${ }^{28}$ reported that aphid reproductive performance is affected by the quality of its diet. Poor nutrition following a disturbance in the feeding process has consequences on the number of ovarioles present in each of the two aphid ovaries, and on the development of embryos in the ovariole. ${ }^{29}$ By removing fewer sugars and amino acids, the aphid would have less raw material for reproduction. It is not the number of samples taken, but rather their duration that is responsible for this reduction in the aphid's diet.

Our data cannot distinguish between CP VOCs affecting aphid behavior directly or indirectly by inducing changes in the host plant. Indirect effects of the VOC methyl jasmonate on aphid feeding via effects on host plants has been shown in one other system. ${ }^{30}$ Indirect effects could be due to changes in host plant metabolism, which could result from changes in its odor, biochemical composition, or its tissue mechanical resistance. Different VOCs could affect plant metabolism. ${ }^{27}$ Kang et al., ${ }^{31}$ also reported that $\beta$-ocimene can activate the host plant defense responses and could be responsible for 
the decrease in the ingestion phase. We found this molecule in the olfactory mixture of $T$. patula in flower, but not in that of $O$. basilicum. We can therefore assume that the basil effect is either due to other VOCs' indirect effect or to a direct effect. A metabolic analysis of the host plant composition would validate the existence of such an indirect effect that the passive adsorption of VOCs from the CPs on the surface of the pepper leaf could be another mode of action. Dancewicz et al., ${ }^{26}$ have demonstrated that certain volatile molecules, such as camphene, can be adsorbed by the leaf of the host plant, and accumulated in mesophyll tissues. Thus, during the probing phases by brief intracellular stylet punctures in these tissues, the detection of these molecules causes the aphid to remove its stylets out of the plant tissue and stylet puncture into another part of the leaf. As a result, the durations of its ingestion phases decrease. ${ }^{27}$ This scenario is consistent with the aphid's feeding behavior that we found in the presence of VOCs from $O$. basilicum and T. patula cv. Nana.

In conclusion, our in vitro tests have demonstrated the effect of CPs on the fecundity of $M$. persicae. We have thus confirmed the ability of $O$. basilicum (vegetative stage) and T. patula (flowering stage) to significantly slow down females’ larviposition, and have highlighted the importance of the chemotype and phenological stage of the CPs, and consequently the composition of the released olfactory mixtures. The ability to decrease the reproduction of the aphid turns out to be an interesting means for screening CPs in addition to their repellent ability, even though, the detachment of plant organs may affect the composition of VOCs. The EPG tests have shown that VOCs produced by both O. basilicum and T. patula in flower strongly disturb the feeding behavior of the aphid. In particular, the significant reduction in feeding time in the phloem should logically result in a reduction in nutritional resources and lead to a decrease in the aphid's fecundity. 
However, further studies are necessary i) to determine whether CPs' VOCs act in a direct and / or indirect way and ii) to reinforce the hypothetical causal link of CPs' VOCs on aphid feeding and its fecundity, which has been shown for the first time in this study. 


\section{REFERENCES}

1. Dedryver CA, Le Ralec A and Fabre F, The conflicting relationships between aphids and men: a review of aphid damage and control strategies. C R Biol 333:539-553 (2010).

2. Stenberg JA, A Conceptual Framework for Integrated Pest Management. Trends Plant Sci 22:759-769 (2017).

3. Cook SM, Khan ZR and Pickett JA, The Use of Push-Pull Strategies in Integrated Pest Management. Annu Rev Entomol 52:375-400 (2007).

4. Zhou H-b, Chen J-l, Liu Y, Francis F, Haubruge E, Bragard C, Sun J-r and Cheng Df, Influence of Garlic Intercropping or Active Emitted Volatiles in Releasers on Aphid and Related Beneficial in Wheat Fields in China. J Integr Agric 12:467473 (2013).

5. Ben Issa R, Gomez L and Gautier H, Companion Plants for Aphid Pest Management. Insects 8:112-131 (2017).

6. Bruce TJA, Wadhams LJ and Woodcock CM, Insect host location: a volatile situation. Trends Plant Sci 10:269-274 (2005).

7. Chapman RF, Bernays EA and Simpson SJ, Attraction and repulsion of the aphid, Cavariella aegopodii, by plant odors. J Chem Ecol 7:881-888 (1981).

8. Dardouri T, Gautier H, Ben Issa R, Costagliola G and Gomez L, Repellence of Myzus persicae (Sulzer): evidence of two modes of action of volatiles from selected living aromatic plants. Pest Manag Sci 75:1571-1584 (2019).

9. Ben Issa R, Gautier H, Costagliola G and Gomez L, Which companion plants affect the performance of green peach aphid on host plants? Testing of 12 candidate plants under laboratory conditions. Entomol Exp Appl 160:164-178 (2016). 
10. Hildebrand DF, Brown GC, Jackson DM and Hamilton-Kemp TR, Effects of some leaf-emitted volatile compounds on aphid population increase. J Chem Ecol 19:1875-1887 (1993).

11. Tomova BS, Waterhouse JS and Doberski J, The effect of fractionated Tagetes oil volatiles on aphid reproduction. Entomol Exp Appl 115:153-159 (2005).

12. de Vos M and Jander G, Volatile communication in plant-aphid interactions. Curr Opin Plant Biol 13:366-371 (2010).

13. Ben Issa R, Gautier H and Gomez L, Influence of neighbouring companion plants on the performance of aphid populations on sweet pepper plants under greenhouse conditions. Agric For Entomol 19:181-191 (2017).

14. Powell G, Tosh CR and Hardie J, Host plant selection by aphids: behavioral, evolutionary, and applied perspectives. Annu Rev Entomol 51:309-330 (2006).

15. Roy HE, Pell JK and Alderson PG, Effects of Fungal Infection on the Alarm Response of Pea Aphids. J Invertebr Pathol 74:69-75 (1999).

16. Tjallingii WF, Electronic recording of penetration behaviour by aphids. Entomol Exp Appl 24:521-530 (1978).

17. Tjallingii WF, Electrical recording of stylet penetration activities, in Aphids, their biology, natural enemies and control, ed. by Minks AK and Harrewijn P, Elsevier Science Publishers: Amsterdam, pp. 95-108 (1988).

18. Martin B, Collar J L, Tjallingii W F and and Fereres A, Intracellular ingestion and salivation by aphids may cause the acquisition and inoculation of non-persistently transmitted plant viruses. J Gen Virol 78:2701-2705 (1997).

19. Giordanengo P, EPG-Calc: a PHP-based script to calculate electrical penetration graph (EPG) parameters. Arthropod-Plant Interact 8:163-169 (2014). 
20. Dardouri T, Gomez L, Schoeny A, Costagliola G and Gautier H, Behavioural response of green peach aphid Myzus persicae (Sulzer) to volatiles from different rosemary (Rosmarinus officinalis L.) clones. Agric For Entomol 21:336-345 (2019).

21. Storer JR and van Emden HF, Antibiosis and antixenosis of chrysanthemum cultivars to the aphid Aphis gossypii. Entomol Exp Appl 77:307-314 (1995).

22. Wang W, Liu Y, Chen J, Ji X, Zhou H and Wang G, Impact of intercropping aphidresistant wheat cultivars withoilseed rape on wheat aphid (Sitobion avenae) and its natural enemies. Acta Ecologica Sinica; 29:186-191 (2009).

23. Rajabaskar D, Ding H, Wu Y and Eigenbrode SD, Behavioral Responses of Green Peach Aphid, Myzus persicae (Sulzer), to the Volatile Organic Compound Emissions from Four Potato Varieties. Am J Potato Res 90:171-178 (2013).

24. Pichersky E and Gershenzon J, The formation and function of plant volatiles: perfumes for pollinator attraction and defense. Curr Opin Plant Biol 5:237-243 (2002).

25. Jiang Y, Ye J, Li S and Niinemets Ü, Regulation of Floral Terpenoid Emission and Biosynthesis in Sweet Basil (Ocimum basilicum). J Plant Growth Regul 35:921935 (2016).

26. Dancewicz K, Sznajder K, Załuski D, Kordan B and Gabryś B, Behavioral sensitivity of Myzus persicae to volatile isoprenoids in plant tissues. Entomol Exp Appl 160:229-240 (2016).

27. Hu H, Li J, Delatte T, Vervoort J, Gao L, Verstappen F, Xiong W, Gan J, Jongsma MA and Wang C, Modification of chrysanthemum odour and taste with chrysanthemol synthase induces strong dual resistance against cotton aphids. Plant Biotechnol J 16:1434-1445 (2018). 
28. Bermingham $\mathrm{J}$ and Wilkinson TL, Embryo nutrition in parthenogenetic viviparous aphids. Physiol Entomol 34:103-109 (2009).

29. Rabatel A, Febvay G, Gaget K, Duport G, Baa-Puyoulet P, Sapountzis P, Bendridi N, Rey M, Rahbé Y, Charles H, Calevro F and Colella S, Tyrosine pathway regulation is host-mediated in the pea aphid symbiosis during late embryonic and early larval development. BMC Genomics 14:235 (2013).

30. Slesak E, Slesak M and Gabrys B, Effect of methyl jasmonate on hydroxamic acid content, protease activity, and bird cherry-oat aphid Rhopalosiphum padi (L.) probing behavior. J Chem Ecol 27:2529-2543 (2001).

31. Kang Z-W, Liu F-H, Zhang Z-F, Tian H-G and Liu T-X, Volatile $\beta$-Ocimene can regulate developmental performance of peach aphid Myzus persicae through activation of defense responses in Chinese cabbage Brassica pekinensis. Frontiers Plant Sci 9:1-12 (2018). 


\section{FIGURE CAPTIONS}

Figure 1. Electropenetrography device (A). The recorded waves (B) were: F - mechanical stress (derailment of the stylets); G - trophic stress (sap ingestion); NP - non-penetration of the stylets; C - search (extracellular paths); E - phloem activity (E1 - salivation; E2 ingestion). pd - "potential drops": it can be subdivided into three sub-phases (II-1, II-2 and II-3).

Figure 2. Daily fecundity of females of Myzus persicae between 8 and 12 days old and placed on a pepper leaf near or far leaves (A, C, E, G, I, J) or flowers (B, D, F, H) of companion plants (mean \pm standard error; $\mathrm{n}=30$ per modality). The degree of significance (P-value) according to the Mann-Whitney U-test $(\alpha=0.05)$ is: NS, difference not significant, $P>0.05 ; * P<0.05 ; * * P<0.01 ; * * * P<0.001$ 
Table 1. VOC mixture constituents released from Tagetes patula var. Nana, for comparison of VOC emitted by the whole flowering plant and VOC emitted by the flower during fecundity trials, sampled by SPME and identified by GC-MS. The VOCs are listed according to their retention time (RT) in minutes.

\begin{tabular}{|c|c|c|c|c|c|}
\hline No. & Compounds & RT & RI & Flowering Tagetes patula cv. Nana plants & Tagetes patula cv. Nana flower \\
\hline 1 & Sabinene & 5.01 & 968 & $x$ & $x$ \\
\hline 2 & $\beta$-Myrcene & 5.20 & 984 & $\times$ & $x$ \\
\hline 3 & (Z)-3-hexenyl acetate & 5.43 & 1002 & $x$ & - \\
\hline 4 & o-Cymene & 5.64 & 1017 & $x$ & $x$ \\
\hline 6 & (E)- $\beta$-Ocimene & 5.78 & 1028 & $\times$ & $x$ \\
\hline 7 & $\beta$-Ocimene & 5.95 & 1042 & $x$ & $x$ \\
\hline 8 & Terpinolene & 6.49 & 1083 & $x$ & $x$ \\
\hline 9 & Linalool & 6.62 & 1094 & $x$ & - \\
\hline 10 & Neo-allo-ocimene & 7.06 & 1122 & $x$ & $x$ \\
\hline 14 & Verbenone & 8.41 & 1207 & $x$ & - \\
\hline 15 & Piperitone & 9.23 & 1251 & $x$ & - \\
\hline 16 & (+)-p-Mentha-1,8-dien-3-one & 9.54 & 1268 & $x$ & - \\
\hline
\end{tabular}




\begin{tabular}{|c|c|c|c|c|c|}
\hline 17 & $\gamma$-Elemene & 10.82 & 1333 & $x$ & - \\
\hline 18 & Eucarvone & 10.91 & 1338 & $\times$ & - \\
\hline 19 & $\beta$-elemene & 11.94 & 1387 & $\times$ & - \\
\hline 20 & $\alpha$-Guaiene & 12.16 & 1398 & $\times$ & $x$ \\
\hline 21 & $\beta$-Caryophyllene & 12.55 & 1417 & $\times$ & $x$ \\
\hline 22 & $\beta$-ylangene & 12.75 & 1426 & $x$ & $x$ \\
\hline 23 & Geranyl acetone & 13.14 & 1445 & $\times$ & - \\
\hline 25 & $\beta$-Cuvebene & 13.47 & 1459 & $\times$ & - \\
\hline 26 & Germacrene D & 13.87 & 1478 & $x$ & - \\
\hline 27 & $\alpha$-Farnesene & 14.35 & 1500 & $\times$ & - \\
\hline 28 & $\beta$-Bisabolene & 14.40 & 1503 & $\times$ & - \\
\hline 29 & $\gamma$-Muurolene & 14.54 & 1509 & $x$ & - \\
\hline
\end{tabular}

RI. retention indices relative to $\left(\mathrm{C}_{8}-\mathrm{C}_{20}\right) \mathrm{n}$-alkane series on a TR-5MS column;

“ $\times$ ”detected compound;

“-”not detected; 
Table 2. VOC mixture constituents released from Ocimum basilicum, for comparison of VOCs emitted by the whole plant and VOCs emitted by the leaves picked during fecundity trials, sampled by SPME and identified by GC-MS. The VOCs are listed according to their retention time (RT) in minutes.

\begin{tabular}{|c|c|c|c|c|c|}
\hline No. & Compounds & RT & RI & Non-flowering Ocimum basilicum plants & Ocimum basilicum leaves \\
\hline 1 & $\alpha$-Pinene & 4.51 & 929 & $x$ & $x$ \\
\hline 2 & Sabinene & 5.01 & 968 & $x$ & $x$ \\
\hline 3 & $\beta$-pinene & 5.05 & 971 & $x$ & $x$ \\
\hline 4 & $\beta$-Myrcene & 5.20 & 984 & $x$ & $x$ \\
\hline 5 & Eucalyptol & 5.73 & 1025 & $x$ & $x$ \\
\hline 6 & Terpinolene & 6.49 & 1083 & $x$ & $x$ \\
\hline 7 & Linalool & 6.62 & 1094 & $x$ & $x$ \\
\hline 8 & Camphor & 7.34 & 1141 & $x$ & $x$ \\
\hline 9 & $\alpha$-Terpineol & 8.08 & 1188 & $x$ & $x$ \\
\hline 10 & Bornyl acetate & 9.78 & 1281 & $x$ & $x$ \\
\hline 11 & Eugenol & 11.24 & 1353 & $x$ & $x$ \\
\hline 12 & Copaene & 11.62 & 1372 & $x$ & $x$ \\
\hline 13 & $\beta$-elemene & 11.94 & 1387 & $x$ & $x$ \\
\hline 14 & Methyleugenol & 12.23 & 1402 & $x$ & $x$ \\
\hline 15 & Aromandendrene & 12.55 & 1417 & $x$ & - \\
\hline 16 & $\alpha$-Bergamotene & 12.85 & 1431 & $x$ & $x$ \\
\hline
\end{tabular}




\begin{tabular}{llcccc}
$\mathbf{1 7}$ & Geranyl acetone & 13.14 & 1445 & $\times$ & $\times$ \\
$\mathbf{1 8}$ & $(E)$ - $\beta$-Famesene & 13.25 & 1449 & $\times$ & $\times$ \\
$\mathbf{1 9}$ & Germacrene D & 13.87 & 1478 & $\times$ & $\times$ \\
$\mathbf{2 0}$ & (Z)- $\beta$-Farnesene & 13.9 & 1480 & $\times$ & $\times$ \\
$\mathbf{2 1}$ & Isomethyleugenol & 14.12 & 1489 & $\times$ & $\times$ \\
$\mathbf{2 2}$ & $\alpha$-Bulnesene & 14.37 & 1501 & $\times$ & $\times$ \\
$\mathbf{2 3}$ & $\gamma$-Muurolene & 14.54 & 1509 & $\times$ & $\times$ \\
$\mathbf{2 4}$ & $\delta$-Cadinene & 14.72 & 1517 & $\times$ & $\times$ \\
$\mathbf{2 5}$ & $\alpha$-epi-Cadinol & 17.24 & 1638 & 25 & 23 \\
\hline Number of compounds identified & & &
\end{tabular}

RI, retention indices relative to $\left(\mathrm{C}_{8}-\mathrm{C}_{20}\right)$ n-alkane series on a TR-5MS column;

“ $X$ ”detected compound;

“-”not detected; 
Table 3. Parameters characterizing the feeding behavior of Myzus persicae placed on pepper plants in the presence or absence (control) of the companion plants Ocimum basilicum at the vegetative stage and Tagetes patula at the flowering stage. The parameters (mean \pm standard error) were calculated using the "EPG-Calc" software over 8 hours of electropenetrography recording carried out on 35 aphids per modality.

\begin{tabular}{|c|c|c|c|}
\hline EPG parameters & Pepper (control) & $\begin{array}{l}\text { Pepper associated with } \\
\text { Ocimum basilicum }\end{array}$ & $\begin{array}{l}\text { Pepper associated with } \\
\text { Tagetes patula cv. Nana }\end{array}$ \\
\hline & $\mathrm{n}=35$ & $\mathrm{n}=35$ & $\mathrm{n}=35$ \\
\hline \multicolumn{4}{|l|}{ General probing behavior } \\
\hline 1. Number of probes & $11.8 \pm 1.4 \mathrm{a}$ & $20.7 \pm 2.4 \mathrm{~b}$ & $22.1 \pm 2.1 \mathrm{~b}$ \\
\hline 2. Total duration of probing (min) & $448.2 \pm 4.1 \mathrm{a}$ & $428.5 \pm 6.3 b$ & $421.3 \pm 9 b$ \\
\hline 3. Time to first probe (min) & $2.8 \pm 0.6 \mathrm{a}$ & $1.6 \pm 0.3 \mathrm{a}$ & $1.35 \pm 0.1 \mathrm{a}$ \\
\hline \multicolumn{4}{|l|}{ Pathway phase (C) } \\
\hline 4. Number of pathway phases & $14.7 \pm 1.6 \mathrm{a}$ & $25.1 \pm 2.6 \mathrm{~b}$ & $26.1 \pm 2.3 \mathrm{~b}$ \\
\hline 5. Total duration of pathway phases (C) (min) & $116.2 \pm 10.2 \mathrm{a}$ & $172.3 \pm 15.4 \mathrm{~b}$ & $184.1 \pm 15.3 b$ \\
\hline \multicolumn{4}{|l|}{ Salivation phase in phloem sap } \\
\hline 6. Number of single salivation phases & $1.6 \pm 0.3 \mathrm{a}$ & $2.8 \pm 0.4 \mathrm{~b}$ & $2.3 \pm 0.4 \mathrm{a}$ \\
\hline 7. Total duration of phloem salivation phase (E1) (min) & $16.1 \pm 2.3$ а & $38.5 \pm 9.4 b$ & $19.3 \pm 2.9 \mathrm{a}$ \\
\hline 8.Time from start to first salivation (min) & $72.1 \pm 9.8 \mathrm{a}$ & $121.8 \pm 19.2 \mathrm{a}$ & $109.8 \pm 19.1 \mathrm{a}$ \\
\hline \multicolumn{4}{|l|}{ Phloem phase: phloem sap ingestion } \\
\hline 9. Number of probes before the first sustained phloem ingestion & $8.1 \pm 1.3 \mathrm{a}$ & $8.4 \pm 1.8 \mathrm{a}$ & $11.2 \pm 1.2 \mathrm{~b}$ \\
\hline 10. Total time of phloem ingestion (min) & $296.7 \pm 16.9 \mathrm{a}$ & $164 \pm 21.7 b$ & $193.1 \pm 21.3 b$ \\
\hline 11. Time from start to first sustained phloem ingestion (min) & $121.1 \pm 15.3 \mathrm{a}$ & $241.1 \pm 27.3 \mathrm{~b}$ & $176.9 \pm 22.5 \mathrm{a}$ \\
\hline \multicolumn{4}{|l|}{ Other parameters } \\
\hline 12. Total duration of stylet derailment $(\mathrm{F})(\mathrm{min})$ & $50.5 \pm 15.16$ a $(9)$ & $53.7 \pm 9.7$ a $(20)$ & $73.7 \pm 14.6$ a $(9)$ \\
\hline 13. Total duration of xylem ingestion $(\mathrm{G})$ (min) & $36.4 \pm 11.1$ a $(6)$ & $51.5 \pm 13.9$ a (17) & $18.6 \pm 4.9$ a $(12)$ \\
\hline
\end{tabular}

14. Number of potential drops (pd)

$114.5 \pm 11.1 \mathrm{a}$

$151.3 \pm 13.9 \mathrm{a}$

$150.5 \pm 12.4 \mathrm{a}$ 


\begin{tabular}{|c|c|c|c|c|c|}
\hline 15. Total duration of pd (min) & $8.1 \pm 0.8 \mathrm{a}$ & $11 \pm 1.1 \mathrm{ab}$ & & $11.2 \pm 0.9 b$ & $\uparrow$ \\
\hline 16. Total duration of sub-phase pd II.1 (min) & $3.2 \pm 0.3 \mathrm{a}$ & $4.3 \pm 0.4 \mathrm{ab}$ & & $4.4 \pm 0.4 \mathrm{~b}$ & 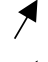 \\
\hline 17. Total duration of sub-phase pd II.2 (min) & $2.1 \pm 0.2 \mathrm{a}$ & $2.9 \pm 0.3 \mathrm{ab}$ & & $2.9 \pm 0.2 \mathrm{~b}$ & $\uparrow$ \\
\hline 18. Total duration of sub-phase pd II.3 (min) & $2.7 \pm 0.2 \mathrm{a}$ & $3.9 \pm 0.3 \mathrm{~b}$ & 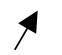 & $3.9 \pm 0.3 \mathrm{~b}$ & 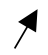 \\
\hline
\end{tabular}

Mean values followed by different letters differ significantly at a 5\% threshold (Mann-Whitney U test).

The values in parenthesis represent the number of aphids that performed phases in which fewer than 35 aphids were available. 

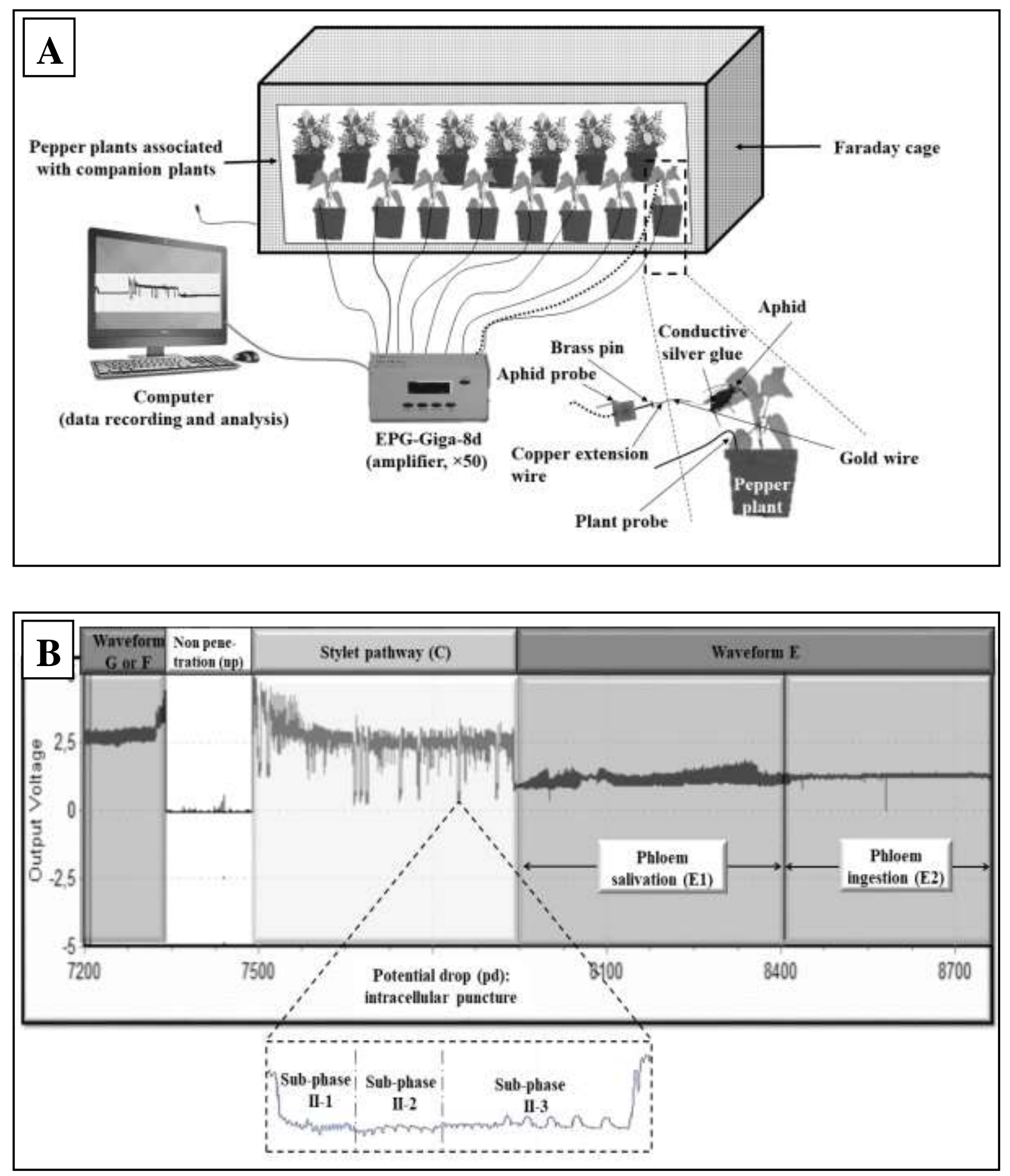

Figure 1. Electropenetrography device (A). The recorded waves (B) were: F mechanical stress (derailment of the stylets); G - trophic stress (sap ingestion); NP non-penetration of the stylets; C - search (extracellular paths); E - phloem activity (E1 salivation; E2 - ingestion). pd - "potential drop": it can be subdivided into three subphases (II-1, II-2 and II-3). 